\title{
Capillary Hemangioma
}

National Cancer Institute

\section{Source}

National Cancer Institute. Capillary Hemangioma. NCI Thesaurus. Code C7457.

A common hemangioma characterized by the presence of capillary-sized vascular channels without prominent epithelioid endothelial cells. 